\title{
INHALT
}

Vorwort .

Teil I

KAPITEL 1

Marcel Pradervand

Der Reformierte Weltbund (RWB)

I. Die Anfänge . . . . . . . . . . . . . . . 15

II. Die Londoner Konferenz . . . . . . . . . . . 16

III. Von der ersten Generalversammlung bis 1914 . . . . 17

IV. Kircheneinheit zwischen zwei Weltkriegen . . . . . . 19

V. Neuer Anfang nach dem Zweiten Weltkrieg . . . . . 25

VI. Reformierter Weltbund in der Okumene . . . . . . 25

VII. Kontakte zu anderen Konfessionsfamilien . . . . . . . 29

VIII. Vereinigung von Reformiertem Weltbund und Internationalem Rat der Kongregationalisten . . . . . . 35

Teil II

Europa

Einleitung . . . . . . . . . . . . . 37

KAPITEL 2

Paul Wieser

Die Reformierten Kirchen der Schweiz

I. Werden und geschichtliche Entwicklung . . . . . . . 41

II. Gegenwärtige kirchliche Strukturen . . . . . . . . 46

III. Kirchenbund und Okumene . . . . . . . . . . 53

IV. Theologische Ausbildung . . . . . . . . . . . 59

Anmerkung . . . . . . . . . . . . . . . . . . 61

KAPITEL 3

Alexander Johannes Bronkhorst

Die Niederländisch-Reformierte Kirche

I. Geschichtlicher Uberblick . . . . . . . . . . . 62

1. Das Jahrhundert der Reformation . . . . . . 62 
2. Die durch den Staat privilegierte Kirche . . . . . . 64

3. Der Kampf um Bekenntnis und Kirchenordnung . . 66

4. Auf dem Wege zur Christus-bekennenden Volkskirche? . 69

II. Gegenwärtige Gestalt und Aktivität . . . . . . . 71

1. Die Kirchenordnung von 1951 . . . . . . . . . 71

2. Kirche und Welt . . . . . . . . . . . . . 74

3. Kirche und Mission . . . . . . . . . . . . . 77

4. Das Bekennen der Kirche . . . . . . . . . . 78

5. Die liturgische Erneuerung . . . . . . . . . . 80

6. Kirche und Okumene . . . . . . . . . . . . . 81

7. Das Verhältnis zur römisch-katholischen Kirche . . 84

III. Die Entwidklungen der letzten Jahre . . . . . . . 86

KAPITEL 4

Rudolf J. Ehrlich

Die Kirche von Schottland

Von der Reformation bis zur Gegenwart

I. Die Kirche reformiert . . . . . . . . . . . . 91

II. Presbyterianismus. . . . . . . . . . . . . . 97

III. Die Covenants . . . . . . . . . . . . . . . 99

IV. Das zweite Episkopalsystem . . . . . . . . . . 102

V. Gemäßigte und Evangelikale . . . . . . . . . . 103

VI. Die Sezessionen . . . . . . . . . . . . . . 104

VII. Die evangelikale Erweckung . . . . . . . . . . 105

VIII. Der Bruch . . . . . . . . . . . . . . . . 106

IX. Entwidklungen im Gottesdienst . . . . . . . . . 107

X. Neubewertung der Westminster Konfession . . . . . 107

XI. Der Wiedervereinigung entgegen . . . . . . . . . 109

XII. Die Erklärenden Artikel . . . . . . . . . . . 110

XIII. Das missionarische Unternehmen . . . . . . . 111

XIV. Die Okumene . . . . . . . . . . . . . . . 112

XV. Die Kirche von Schottland heute . . . . . . . . . 114

Anhang:

A. Auszüge aus dem Kürzeren Katechismus . . . . . . . 116

B. Erklärende Artikel zu der Verfassung der Kirche

von Schottland in geistlichen Angelegenheiten 
KAPITEL 5

Paul Jacobs

Die Reformierten Kirchen Deutschlands

Geschichte und Gegenwart

I. Geschichte und gegenwärtige Gestalt . . . . . . . 118

II. Bekenntnis und gegenwärtige theologische Fragen . . . 124

III. Stellung zur Okumene, zu den jungen Kirchen, zum Stazt und zur modernen Welt . . . . . . . . 136

Nachtrag des Herausgebers . . . . . . . . . . . . . 143

Anhang:

Auszüge aus dem Heidelberger Katechismus . . . . . . 147

KAPITEL 6

Roger Mehl

Die Reformierte Kirche von Frankreich

I. Geschichtlicher Uberblick . . . . . . . . . 150

1. Von den Anfängen bis zur Revolution . . . . . . 150

2. Revolution und Restauration . . . . . . . . . 156

3. Die Evangelisationsbewegung . . . . . . . . . 157

4. Auf dem Weg zur einen Kirche. . . . . . . . . 159

II. Die gegenwärtige Situation . . . . . . . . . . . 160

1. Stagnation oder Rückgang . . . . . . . . . . 160

2. Neue Unternehmungen . . . . . . . . . . . 162

3. Gemeinde und Pastoren . . . . . . . . . 163

4. Theologische Strömungen . . . . . . . . . . 166

5. Politische Verantwortung . . . . . . . . . . 167

6. Suche nach Einheit . . . . . . . . . . . . . 169

7. Biblische Erneuerung . . . . . . . . . . . 171

Anmerkungen . . . . . . . . . . . . . . . 172

KAPITEI 7

Giorgio Tourn

Die Waldenserkirche

Vergangenheit und Zukunft

I. Einsicht in die Vergangenheit . . . . . . . . . . 174

1. Die "Internationale der Armen ${ }^{\alpha}$. . . . . . . . 174

2. Jahrhunderte der Verfolgung . . . . . . . . 176

3. In Richtung auf eine neue Diaspora . . . . . . . 179

4. Vom Widerstand zu einem positiven Gegenzeugnis . . 182 
II. Die gegenwärtige Lage . . . . . . . . . . . . 185

1. Eine Minderheit von 0,5 Prozent . . . . . . . . 185

2. Die missionarische Berufung . . . . . . . . . 186

3. Kirche oder Bewegung . . . . . . . . . . . 189

4. Zwischen der ersten und der zweiten Reformation . . 190

III. Das Problem des Okumenismus und der Mission . . . . 192

Nachtrag des Herausgebers . . . . . . . . . . . . . 197

Anmerkungen . . . . . . . . . . . . . . . 197

KAPITEL 8

Amadeo Molnár

Die Evangelische Kirche der Böbmischen Brüder

I. Rückblick . . . . . . . . . . . . . . . . 199

II. Werden, Ausbreitung, Struktur, Lebensformen . . . . 202

III. Werdegang der theologischen Besinnung . . . . . . 205

IV. Okumenische Beziehungen . . . . . . . . . . . 213

KAPITEL 9

Tibor Bartha

Die Reformierte Kirche von Ungarn

Geschichte und Gegenwart

I. Geschichte und gegenwärtige Lage . . . . . . . . 217

1. Historische Grundzüge . . . . . . . . . . . 217

2. Die Bahnbrecher der ungarischen Reformation . . 219

3. Die Puritanerbewegung in Ungarn . . . . . . . 221

4. Die Gegenreformation . . . . . . . . . . . 222

5. Die Zeit der unblutigen Gegenreformation

(1711-1718). . . . . . . . . . . . . . 223

6. Das Toleranzedikt Josefs II. und dessen

Auswirkungen . . . . . . . . . . . . . . 224

7. Das Zeitalter des Liberalismus . . . . . . . . . 225

8. Die Zeit der beiden Weltkriege . . . . . . . . . . . . 227

9. Die reformierte Kirche in der neuen Gesellschaft . . . 229

II. Das Bekenntnis und die Organisation

der Reformierten Kirche von Ungarn . . . . . . . 232

1. Die Bekenntnisschriften und ihre heutige

Bewertung . . . . . . . . . . . . 232

2. Die Organisation der Kirche . . . . . . . . . 234 
III. Die Reformierte Kirche von Ungarn und die Okumene . . . . . . . . . . . . 236

Anmerkung . . . . . . . . . . . . . . . . 239

KAPITEL 10

Istvan Juhász

Die Reformierte Kirche in der Volksrepublik Rumänien

Ein geschichtlicher Uberblidk

I. Daten zur Information . . . . . . . . . . . 240

1. Geographische Lage . . . . . . . . . 240

2. Historischer Abriß. . . . . . . . . . . . 240

3. Einwohnerzahl . . . . . . . . . . . . . 241

4. Mitgliederzahl der reformierten Kirche . . . . . . 241

II. Die Reformation . . . . . . . . . . . . . . 241

III. Das Zeitalter des reformierten Konfessionalismus und Puritanismus . . . . . . . . . . . . . 248

IV. Das Zeitalter der Unterdrückung und des protestantischen Liberalismus . . . . . . . . 255

V. Die heutige Zeit . . . . . . . . . . . . . 262

\section{Teil III}

Amerika

Einleitung . . . . . . . . . . . . . . . 267

KAPITEL 11

Howard G. Hageman

Die Reformierte Kirche in Amerika

I. Die Siedlerkirche . . . . . . . . . . . . . . 270

II. Versuche einer Selbstverwaltung . . . . . . . . . 272

III. Unabhängige Kirche . . . . . . . . . . . . . 275

IV. Separationen . . . . . . . . . . . . . . . 277

V. Einwanderungsfolgen im 19. Jahrhundert . . . . . . 280

VI. Theologische Richtungen . . . . . . . . . . . 282

VII. Gottesdienstordnung. . . . . . . . . . . . . 285

VIII. Kirchenordnung . . . . . . . . . . . . . 287 
IX. Mission und Okumene . . . . . . . . . . . . 288

X. Unionsversuche . . . . . . . . . . . . . . 289

XI. Konservative Aktualität . . . . . . . . . . . 291

Anmerkung . . . . . . . . . . . . . . . . . 293

\section{Teil IV}

Afrika und Asien

Einleitung . . . . . . . . . . . . . . 295

KAPITEL 12

Willem Adolf Landman

Die Holländische Reformierte Kirche in Südafrika

I. Historischer Hintergrund . . . . . . . . . . . 297

1. Ausdehnung nach Norden und Osten . . . . . . 299

2. Urbanisierung . . . . . . . . . . . . 302

3. Andere reformierte Kirchen . . . . . . . . . 303

II. Christliche Missionen . . . . . . . . . . . . 303

1. Missionspolitik . . . . . . . . . . . . . 306

2. Gemeinden bei der Arbeit . . . . . . . . . 307

3. Okumenische Zusammenarbeit und die Missionen . . 308

4. Fürsorge, Krankenhäuser und Bildungswesen . . . . 309

5. Zusammenfassung . . . . . . . . . . . . . 309

6. Liste der holländisch-reformierten Kirchen . . . . . 311

III. Theologische Ausbildung und Denkrichtungen . . . . 312

IV. Erziehungs- und Fürsorgedienst . . . . . . . . . 313

V. Finanzen . . . . . . . . . . . . . . . . . 314

VI. Okumenismus . . . . . . . . . . . . . . . 315

VII. Das Zeugnis der Kirche in der rasch sich wandelnden Gesellschaft . . . . . . . . 316

VIII. Die Holländische Reformierte Kirche und die Politik der getrennten Entwicklung . . . . . . . . . 317

KAPITEL 13

David Petrus Botha

Die Holländische Reformierte Missionskirche in Südafrika

I. Ursprünge . . . . . . . . . . . . . . . . 324 
II. Das Verhältnis zur Familie der Holländischen Reformierten Kirchen . . . . . . . . . . . . 326

III. Ausbildung der Pfarrer . . . . . . . . . . . . 327

IV. Struktur und Funktion der Kirche . . . . . . . . . 328

V. Abteilung für Verwaltung und Finanzen . . . . . . 329

VI. Abteilung für den Dienst der Barmherzigkeit . . . . 330

VII. Abteilung für Jugendarbeit . . . . . . . . . . 332

VIII. Evangelisation und Mission . . . . . . . . . 333

IX. Abteilung für Publizistik und Kommunikation . . . . 335

X. Okumenische Beziehungen . . . . . . . . . . . 335

XI. Probleme und Entscheidungen . . . . . . . 336

XII. Statistik . . . . . . . . . . . . . . . . 340

KAPITEL 14

Christian G. Baeta

Kirchen der reformierten Tradition in den Republiken

Ghana und Togo (Westafrika)

I. Einleitung . . . . . . . . . . . . . . . . 342

II. Christliche Geschichte Westafrikas . . . . . . . 343

III. Die Presbyterianische Kirche von Ghana . . . . . . 345

Anmerkung . . . . . . . . . . . . . 352

KAPITEL 15

Fridolin Ukur

Die Kirchen in Indonesien

Eine kurze Geschichte

I. Vom Ort, an dem die Kirchen leben . . . . . . . . 353

II. Die Ur-Geschichte der Kirchen in Indonesien . . . . . 355

1. Die Anfänge (ca. 645-ca. 1500) . . . . . . . . 355

2. Die katholische Kirche kommt nach Indonesien 1511-1666 . . . . . . . . . . . . . . 355

III. Die Ausbreitung protestantischen Christentums in Indonesien 1605-1930 . . . . . . . . . . . 357

IV. Das Entstehen von regionalen ethnischen Kirchen 1830-1930 . . . . . . . . . . . . . . . . 359

1. Der Einfluß der ökumenischen Bewegung . . . . . 361

2. Der Einfluß der nationalen Bewegung . . . . . . 361 
V. Die Geschichte der Kirchen in Indonesien in der Neuzeit . . . . . . . . . . . . . . . 362

1. Kirche und Nationalismus 1930-1941 . . . . . . 362

2. Die Kirche in der Zeit der japanischen Besetzung 1942-1945 . . . . . . . . . . . . . . . 364

3. Die Kirche wird mündig . . . . . . . . . . . 366

4. Die Kirche in der Zeit des Unabhängigkeitskrieges 1945-1950. . . . . . . . . . . . . 367

VI. Die wachsende Kirche 1950 bis heute . . . . . . . 369

1. Der Rat der Kirchen in Indonesien wird gegründet . . . . . . . . . . . . . . . 369

2. Das Wachstum der Kirchen in Indonesien . . . . . 369

3. Der Kampf der Kirche im politischen Leben . . . . 371

4. Die Kirchen Indonesiens in der ökumenischen Bewegung. . . . . . . . . . . . . . . . 373

5. Kirche inmitten einer pluralistischen Gesellschaft . . 373

6. Kirchen und Missionsgruppen außerhalb des Rates der Kirchen . . . . . . . . . . . . . . . 374

7. Vorbereitung auf die Zukunft . . . . . . . . . . 375

Nachwort . . . . . . . . . . . . . 376

Anhang . . . . . . . . . . . . . . 377

Mitarbeiterverzeichnis . . . . . . . . . . . 377

Literaturverzeichnis . . . . . . . . . . . . . . 379

Der Reformierte Weltbund (RWB) . . . . . . . . . . 387

Mitgliedskirchen des Reformierten Weltbundes (RWB) . . . 388

Statistik . . . . . . . . . . . . . . . . . 399 